\title{
Evaluation of Characteristics and Clinical Outcomes of Patients with Cardiac Arrest
}

\author{
Yasemin Ece ${ }^{1}$, Erden Erol Ünlüer ${ }^{2}$, Ali Kemal Erenler ${ }^{3}$, Aslı Şener ${ }^{4}$ \\ 'Department of Emergency Medicine, Private Medifema Hospital, İzmir, Turkey \\ 2Department of Emergency Medicine, Uşak University Hospital, Uşak, Turkey \\ ${ }^{3}$ Department of Emergency Medicine, Hitit University Çorum Education and Research Hospital, Çorum, Turkey \\ ${ }^{4}$ Clinic of Emergency Medicine, Çiğli Region Education Hospital, İzmir, Turkey
}

\begin{abstract}
Aim: Cardiopulmonary resuscitation (CPR) is an important and common intervention in emergency settings. In this article, we aimed to determine the characteristics and outcomes of the patients on whom CPR was performed in the emergency department (ED).

Materials and Methods: We retrospectively investigated the medical records of 295 patients with cardiopulmonary arrest over a two-year period. The patient's, age, sex, arrival time, route of arrival, reasons for admission, medical history, whether CPR was performed before arrival, whether intubation was performed, whether CPR was performed after arrival, whether defibrillation was performed, whether rapid sequence intubation (RSI) was performed, outcome (death, admission to an intensive care unit, an angiography unit, or a ward), and period of hospitalization were recorded.

Results: Most of the patients were brought by ambulance, and asystoly was the most common initial rhythm. In 182 patients, CPR was initiated before admission to the ED. All 26 patients with malignity died. Of the patients with a medical history of multiple diseases, $91.4 \%$ ( $n=32)$ died. RSI was performed in 19 patients (6.4\%), and defibrillation was performed in 49 patients (16.6\%). It was determined that 253 patients (85.8\%) died after CPR.

Conclusion: In our study, asystoly was found to be the most common initial rhythm in patients with cardiopulmonary arrest. Our study also revealed that patients with co-morbidity and patients requiring RSI had lower rates of survival.
\end{abstract}

Keywords: Emergency department, cardiac arrest, cardiopulmonary resuscitation

\section{Introduction}

Cardiopulmonary arrest (CPA) is defined as the sudden and unexpected interruption of respiration and/or circulation (1). In clinical practice, it refers to the "absence of cardiac mechanical activity." Clinical diagnosis is confirmed with unresponsiveness, pulselessness, and apnea. The term "cardiopulmonary resuscitation" (CPR) refers to interventions aimed to maintain vitality in a patient whose life is interrupted (2). In the US, 250,000-400,000 cardiac death incidents are reported annually. Cardiac deaths constitute $20 \%$ of all mortality in the western world $(3,4)$.

Resuscitation of a patient with CPA is a time-sensitive process that requires coordination between a number of health providers (5). It is accepted that outcomes of CPR depend on three basic factorsearly and effective CPR, optimized response time, and early defibril- lation. It is reported that early defibrillation within 5-7 minutes after sudden cardiac arrest increases survival up to $30-45 \%$ (6). As the time before CPR grows longer, the chance of survival decreases. Every extra minute decreases the survival rate by about $10 \%(7,8)$.

In this study, our aim was to investigate the efficiency of updated CPR methods and Emergency Cardiac Care guidelines on the outcomes of CPR.

\section{Materials and Methods}

In this cross-sectional retrospective study, medical records of patients of all ages who required CPR $(n=295)$ in our emergency department (ED) were investigated between January 1, 2010, and December 31, 2011. Those who died before arrival to our ED $(n=11)$ were excluded from the study.

Correspondence to: Yasemin Ece e-mail:yasemin_dr@yahoo.com 
From the medical records, the patient's age, sex, arrival time, route of arrival, reasons for admission, medical history, whether CPR was performed before arrival, whether intubation was performed, whether CPR was performed after arrival, whether defibrillation was performed, whether rapid sequence intubation (RSI) was performed, outcome (death, admission to an intensive care unit, an angiography unit, or a ward), and the period of hospitalization were recorded.

\section{Statistical analysis}

For the statistical analysis, the Statistical Package for the Social Sciences (SPSS Inc.; Chicago, IL, USA) 15.0 program was used. Descriptive statistics were given as median and standard deviation for numeric variables and as number and percentage for categorical variables. The chi-square and Fisher's Exact tests were used for comparing categorical variables. Because numerical variables were not normally distributed between groups (Kolmogorov-Smirnov, $\mathrm{p}<0.05)$, the Mann-Whitney $U$ test was used when comparing two groups and the Kruskal-Wallis $\mathrm{H}$-analysis was used for comparing more than two groups. A $p$ value $<0.05$ was considered statistically significant.

\section{Results}

Of the 295 patients involved, 110 (37.3\%) were female and 185 $(62.7 \%)$ were male. The mean age of the patients was $64.13 \pm 18.9$ years, and the mean age of males was significantly lower than females $(\mathrm{p}<0.05)$. [95\% Cl; $(-14.5)-(-5.8)]$.

Patients were mostly admitted between 12:00 and 00:00 $(n=187)$, and between the hours of 20:00 and 21:59 was the most common time of admittance.

Of the 230 patients admitted to the resuscitation room at the time of arrival, $78 \%$ had been brought by an ambulance.

When medical histories of the patients were investigated, it was determined that 26 patients $(8.8 \%)$ had a malignity such as a unique disease and 35 patients (11.9\%) had a history of multiple diseases. We could not determine the medical histories of 172 patients (58.3\%).

Asystoly was the most common rhythm at the time of arrival $(n=69,23.4 \%)$ followed by ventricular fibrillation (VF) $(n=31,10.55 \%)$ and pulseless electrical activity (PEA) $(n=25,8.5 \%)$.
Cardiopulmonary resuscitation was performed in 223 patients (75.6\%), and 195 (66.1\%) were intubated only. In 182 patients, CPR was initiated before admission to the ED.

Rapid sequence intubation was performed in 19 patients (6.4\%), and defibrillation was performed in 49 patients (16.6\%).

It was determined that 253 patients (85.8\%) died after CPR ( $85.9 \%$ of the 159 male patients died and $85.5 \%$ of the 94 female patients died). The difference between the sexes was not statistically significant ( $p>0.05)$.

All 26 patients with malignity died. Of the patients with a medical history of multiple diseases, $91.4 \%(n=32)$ died. Comparisons of these two variables with other parameters were statistically significant (Table 1).

Of the 139 patients who arrived in an ambulance, $60.4 \%$ died, and the mean length of hospital stay for patients arriving by ambulance was $4.2 \pm 14.5$ days.

The rhythms of 86 patients could not be determined. The second-largest group was the asystoly group ( $n=63$ ). Our study also revealed that 83 of the patients with unshockable rhythm on admission died (88.3\%). A statistical significance was seen when patients were compared according to the initial rhythms (Table 2). Patients with asystoly on admission had the longest length of stay in the hospital when compared to other rhythms.

Patients who required RSI had a 0.24 -fold greater risk of death when compared to those who did not. This finding was statistically significant (OR: 0.249, 95\% Cl: 0.092-0.675).

When laboratory findings of the patients were evaluated, it was determined that higher glucose levels were associated with higher mortality. Other parameters did not affect the mortality rate.

\section{Discussion}

It is estimated that 60 million people die in the world annually, and ischemic heart diseases are the most common cause of death among adults (9-11). In the literature, the mean age of patients who die due to cardiac arrest is reported to be 68 years (12). The mean age of patients in our study was $64.1 \pm 19$ years $(60.3 \pm 19.2$ years in males, $70.5 \pm 16.8$ years in females). The lower age in our population is thought to be linked to socioeconomic and geographic factors.

Table 1. Comparison of outcomes of patients according to co-morbidities

\begin{tabular}{|c|c|c|c|c|c|c|c|c|}
\hline \multirow[b]{3}{*}{ History } & \multicolumn{4}{|c|}{ Outcome } & & & \multirow[b]{3}{*}{$\mathbf{p}$} & \multirow[b]{3}{*}{$95 \% \mathrm{Cl}$} \\
\hline & \multicolumn{2}{|c|}{ Death } & \multicolumn{2}{|c|}{ Discharge } & \multicolumn{2}{|c|}{ Total } & & \\
\hline & $\mathbf{n}$ & $\%$ & $\mathbf{n}$ & $\%$ & $\mathbf{n}$ & $\%$ & & \\
\hline Malignity & 26 & 100.0 & - & 0.0 & 26 & 100.0 & \multirow{7}{*}{0.001} & \multirow{7}{*}{$\begin{array}{c}0.000 \\
- \\
0.001\end{array}$} \\
\hline Cardiac & 16 & 69.6 & 7 & 30.4 & 23 & 100.0 & & \\
\hline Respiratory & 6 & 75.0 & 2 & 25.0 & 8 & 100.0 & & \\
\hline Kidney & 5 & 71.4 & 2 & 28.6 & 7 & 100.0 & & \\
\hline Others & 10 & 58.8 & 7 & 41.2 & 17 & 100.0 & & \\
\hline Multiple & 32 & 91.4 & 3 & 8.6 & 35 & 100.0 & & \\
\hline Unknown & 153 & 88.9 & 19 & 11.1 & 172 & 100.0 & & \\
\hline
\end{tabular}


Table 2. Outcomes of the patients according to initial rhythms

\begin{tabular}{|c|c|c|c|c|c|c|c|c|c|c|c|}
\hline & & \multicolumn{6}{|c|}{ Initial rhythm Total } & \multirow{2}{*}{\multicolumn{2}{|c|}{ Total }} & \multirow[b]{3}{*}{$\mathbf{p}$} & \multirow[b]{3}{*}{$95 \% \mathrm{Cl}$} \\
\hline & & \multicolumn{2}{|c|}{$\begin{array}{c}\text { Unshockable } \\
\text { rhythm } \\
\text { (Asystoly+PEA) }\end{array}$} & \multicolumn{2}{|c|}{$\begin{array}{c}\text { Shockable } \\
\text { rhythm } \\
\text { (VF+Pulseless VT) }\end{array}$} & \multicolumn{2}{|c|}{$\begin{array}{c}\text { Others } \\
\text { (SR+AF+ } \\
\text { Block+Unknown) }\end{array}$} & & & & \\
\hline \multicolumn{2}{|l|}{ Outcome } & $\mathbf{n}$ & $\%$ & $\mathbf{n}$ & $\%$ & $\mathbf{n}$ & $\%$ & $\mathbf{n}$ & $\%$ & & \\
\hline \multirow{2}{*}{ Death } & $\mathrm{n}$ & 83 & 46.9 & 23 & 13.0 & 71 & 40.1 & 177 & 100.0 & \multirow{12}{*}{0.001} & \multirow{12}{*}{$\begin{array}{c}0.001 \\
- \\
0.003\end{array}$} \\
\hline & $\%$ & 88.3 & & 56.1 & & 44.4 & & 60.0 & & & \\
\hline \multirow{2}{*}{$\mathrm{ICU}$} & $\mathrm{n}$ & 6 & 8.1 & 13 & 17.6 & 55 & 74.3 & 74 & 100.0 & & \\
\hline & $\%$ & 6.4 & & 31.7 & & 34.4 & & 25.1 & & & \\
\hline \multirow{2}{*}{ Ward } & $\mathrm{n}$ & 4 & 12.9 & 2 & 6.5 & 25 & 80.6 & 31 & 100.0 & & \\
\hline & $\%$ & 4.3 & & 4.9 & & 15.6 & & 10.5 & & & \\
\hline \multirow{2}{*}{ Angiography } & $\mathrm{n}$ & 1 & 16.7 & 3 & 50.0 & 2 & 33.3 & 6 & 100.0 & & \\
\hline & $\%$ & 1.1 & & 7.3 & & 1.3 & & 4.4 & & & \\
\hline \multirow{2}{*}{ Surgery } & $n$ & 0 & 0.0 & 0 & 0.0 & 7 & 100.0 & 7 & 100.0 & & \\
\hline & $\%$ & 00 & & 0.0 & & 4.4 & & 2.4 & & & \\
\hline \multirow{2}{*}{ Total } & $n$ & 94 & 31.9 & 41 & 13.9 & 160 & 54.2 & 295 & 100.0 & & \\
\hline & $\%$ & 100.0 & & 100.0 & & 100.0 & & 100.0 & & & \\
\hline
\end{tabular}

In a study in Turkey, Erenler et al. (13) investigated trauma patients requiring CPR over a 5-year period and found the survival rate to be $9.5 \%$. In our study, $14.2 \%$ of the patients were successfully resuscitated and survived. The reason for the greater survival rate in our study might be associated with the possibility of unpredictable injuries that multiple-trauma patients might have.

In a study by Wuerz et al. (14), it was reported that age did not affect the success of resuscitation. The main factors for success were reported to be early CPR and advanced cardiac life support, and our results are in agreement with the literature. Seven patients discharged after a successful resuscitation were over 80 years old.

In a study by Schears et al. (15), it was found that the success of CPR in patients with comorbid diseases, terminal cancer, and irreversible disease was low. In our study, the success of CPR in 123 patients with multiple diseases was lower than those with cancer alone.

Land ambulance was the most common route of arrival to the ED (78.5\%), and the least common route was air ambulance (4\%). Although there are reports in the literature that higher survival rates are obtained in patients arriving by air ambulance, we found no statistical significance between these two routes $(16,17)$. Patient transfer by air ambulance has only been present in Turkey since 2008 , so it is still a developing field in the healthcare system.

Asystoly (44.2\%), followed by VF (19.9\%), were found to be the most common initial rhythms before cardiac arrest in our study. In the literature, it is reported that asystoly is more common than shockable rhythms (18). The higher frequency of unshockable rhythms might be associated with prolonged arrest, difficulties in recognizing cardiac arrest in a timely manner, or delayed activation of the emergency services. In developed countries, the frequency of VF outside of the hospital tends to decrease due to widespread use of automated external defibrillators in public places (19). Patients with PEA had the highest mortality rate $(95.7 \%)$, followed by asystoly $(88.4 \%)$. The ma- jority of the patients who died (46.9\%) had unshockable rhythms on admission. When all patients who required CPR were investigated, $34.7 \%$ had asystoly, and $88.4 \%$ of these patients died. In the literature, it is reported that CPR after asystoly has the lowest rate of survival (20).

In another study, it was determined that the most common initial rhythm in patients requiring CPR was asystoly (39\%). In addition, when initial rhythms were investigated, the number of patients discharged from the hospital was found to be greater in patients with PEA when compared to those with asystoly and greater in patients with VT/VF when compared to those with PEA/asystoly. The hospital discharge rate was found to be higher in patients with shockable rhythms. Among unshockable rhythms, the discharge rate was higher in the PEA group than the asystoly group (21). In our study, PEA was found to have the highest mortality rate.

The mortality rate of patients on whom RSI was performed was lower than those who did not receive RSI (63.2\% vs. $87.3 \%)$. Thus patients who underwent early airway protection had higher survival rates. This finding was also compatible with the literature where it is reported that RSI performed in the ED is both effective and safe (22).

We could obtain laboratory findings for 163 patients (55.2\%) admitted to the resuscitation room. The glucose levels of $73.6 \%$ of the patients who died were high. It was also found that the AST and ALT levels of all the patients who required care in the resuscitation room were high. In the literature, there is a lack of laboratory investigations of patients who require CPR; however, in a previous study, an electrolyte imbalance was seen in $45 \%$ of the patients, and elevation of AST/ ALT in patients admitted to the resuscitation room was also seen (23).

\section{Study limitations}

Our study also has some limitations. First, as mentioned above, we could not obtain medical records for 172 patients. Such a number 
of patients without a medical record might affect our results regarding the relationship between cardiac arrest occurrence and co-morbidities. Second, we were unable to determine the initial rhythms of 86 patients due to the chaotic environment in the ED at the time of the patient's arrival. Third, it is possible that higher rates of RSI might have been obtained with an emergency team that was more experienced and skilled in the technique.

\section{Conclusion}

Sudden cardiac death constitutes $20 \%$ of all deaths, and about half of these deaths occur in pre-hospital settings. Features associated with survival from CPA cases are known to be the presence of VF as the initial rhythm and early CPR either pre or in-hospital. Additionally, effective CPR in the ED, avoiding hyperventilation, and post-resuscitative care are other factors positively affecting mortality and morbidity. Our study revealed that patients with co-morbidity and patients requiring $\mathrm{RSI}$ had lower rates of survival.

Ethics Committee Approval: Ethics committee approval was received for this study from the ethics committee of Izmir Katip Çelebi University (Decision No: 91, 10/12/2012).

Peer-review: Externally peer-reviewed.

Conflict of Interest: No conflict of interest was declared by the authors.

Financial Disclosure: The authors declared that this study has received no financial support.

\section{References}

1. Ozkose Z. Erişkinler İçin Kardiyopulmoner Resüsitasyon: I- Temel Yaşam Desteği. Gazi Med J 2005; 16: 3-13.

2. Jacobs I, Nadkarni V, Bahr J, Berg RA, Billi JE, Bossaert L, et al. Cardiac arrest and cardiopulmonary resuscitation outcome reports: update and simplification of the Utstein templates for resuscitation registries: a statement for healthcare professionals from a task force of the International Liaison Committee on Resuscitation (American Heart Association, European Resuscitation Council, Australian Resuscitation Council, New Zealand Resuscitation Council, Heart and Stroke Foundation of Canada, InterAmerican Heart Foundation, Resuscitation Councils of Southern Africa). Circulation 2004; 110: 3385-97. [CrossRef]

3. Sung RJ, Kuo CT, Wu SN, Lai WT, Luqman N, Chan NY. Sudden Cardiac Death Syndrome: Age, Gender, Ethnicity, and Genetics. Acta Cardiolgica Sinica 2008; 24: 65-74

4. Lee KK, Amin AA, Wang PJ, Myerburg RJ. Epidemiology and Etiologies of Sudden Cardiac Death. in Wang Paul J, Al-Ahmad A, Hsia Henry H, Zei Paul C Eds. Ventricular Arrhythmias and Sudden Cardiac Death 2008, Blackwell Publishing, 199-212. [CrossRef]

5. Zipes DP, Wellens HJ. Sudden Cardiac Death. Circulation 1998; 98: 233451. [CrossRef]

6. Priori SG, Alliot E, Blømstrom-Lundqvist C, Bossaert L. Ani Kardiyak Ölüm. Avrupa Kardiyoloji Derneği Çalışma Grubu ESC Kılavuzu, Türk Kardiyoloji
Derneği Adalet K, Gürdal M, Mutlu B, çeviri editörleri, France: European Society of Cardiology 2003.

7. Donmez AA. Kanıta dayalı kardiyoloji el kitabı. İçinde: Kozan O, çeviri editörü. Ani kardiyak ölüm ve ICD tedavisi. İstanbul: Avrupa Tıp Kitapçוık Ltd. Şti 2009; 95-106.

8. European Heart Rhythm Association.; Heart Rhythm Society., Zipes DP, Camm AJ, Borggrefe M, Buxton AE, Chaitman B, et al. ACC/AHA/ESC 2006 guidelines for management of patients with ventricular arrhythmias and the prevention of sudden cardiac death: a report of the American College of Cardiology/American Heart Association Task Force and the European Society of Cardiology Committee for Practice Guidelines (Writing Committee to Develop Guidelines for Management of Patients With Ventricular Arrhythmias and the Prevention of Sudden Cardiac Death). J Am Coll Cardiol 2006; 48: e247-346. [CrossRef]

9. Available at www.who.int/gho/mortality_burden_disease/en/index.html. WHO website, accessed 25.03.2012.

10. Available at www.nvi.gov.tr/Hizmetler/lstatistikler,Dogum_Olum_.statistikleri.html, accessed 25.03.2012.

11. Unuvar N, Mollahaliloğlu S, Yardim N. UHY-ME Çalışması, Türkiye T.C. Sağlık Bakanlığı, Refik Saydam Hıffızsıhha Merkezi Başkanlığı, Hıffızsıha Mektebi Müdürlüğü Yayınları, 2004; 6.

12. Petrie DA, De Maio V, Stiell IG, Dreyer J. Factors affecting survival after prehospital asystolic cardiac arrest in a Basic Life Support - defibrillation system, OPALS study. CJEM 2001; 3: 186-92. [CrossRef]

13. Erenler AK, Çelik S, Baydin A, Tomak L, KoSargelir M, Yasti AÇ. Outcomes of cardiopulmonary resuscitation in trauma patients in the Emergency Department. Eur Rev Med Pharmacol Sci 2015; 19: 2567-71.

14. Wuerz RC, Holliman J, Meador SA, Swope GE, Balogh R. Effect of age on prehospital cardiac resuscitation outcome. Am J Emerg Med 1995; 13: 389-91. [CrossRef]

15. Schears RM, Marco CA, Iserson KV. "Do Not Attempt Resuscitation" (DNAR) in the out-of-hospital setting. Ann Emerg Med 2004; 44: 68-70. [CrossRef]

16. Galvagno SM Jr, Haut ER, Zafar SN, Millin MG, Efron DT, Koenig GJ Jr, et al. Association between helicopter vs ground emergency medical services and survival for adults with major trauma. JAMA 2012; 307: 1602-10. [CrossRef]

17. McCoy CE, Menchine M, Sampson S, Anderson C, Kahn C. Emergency medical services out-of-hospital scene and transport times and their association with mortality in trauma patients presenting to an urban Level I trauma center. Ann Emerg Med 2013; 61: 167-74. [CrossRef]

18. Nadkarni VM, Larkin GL, Peberdy MA, Carey SM, Kaye W, Mancini ME, et al. National Registry of Cardiopulmonary Resuscitation Investigators. First documented rhythm and clinical outcome from in-hospital cardiac arrest among children and adults. JAMA 2006; 295: 50-7. [CrossRef]

19. Bunch TJ, White RD, Friedman PA, Kottke TE, Wu LA, Packer DL. Trends in treated ventricular fibrillation out-of-hospital cardiac arrest: a 17-year population-based study. Heart Rhythm 2004; 1: 255-9. [CrossRef]

20. Candan I, Oral D. Ani Kardiyak Ölüm. Kardiyoloji, Ankara, Antıp A.Ş. 2002, 590-600

21. Meaney PA, Nadkarni VM, Kern KB, Indik JH, Halperin HR, Berg RA. Rhythms and outcomes of adult in-hospital cardiac arrest. Crit Care Med 2010; 38: 101-8. [CrossRef]

22. Dufour DG, Larose DL, Clement SC. Rapid sequence intubation in the emergency department. J Emerg Med 1995; 13: 705-10. [CrossRef]

23. Bjork RJ, Snyder BD, Campion BC, Loewenson RB. Medical complications of cardiopulmonary arrest. Arch Intern Med 1982; 142: 500-3. [CrossRef] 